\title{
Socio-political evolution of Central Asian clans
}

\author{
D. A. Rekk ${ }^{1}$, V. G. Yegorov ${ }^{1}$
}

1Moscow regional state University, 7/10 p. 3 Bolshaya Polyanka str., Moscow 119180, Russian Federation

DOI: $10.18255 / 2412-6519-2020-3-250-259$

Research Article

Full text in Russian

The article is devoted to the clan organization of the post-Soviet countries of Central Asia. Recently, scientific interest in the stated topic has decreased somewhat, due to the lack of implementation of traditional institutions of Eastern societies and the decline in the influence of the liberal mainstream on the socio-political process in post-Soviet Asia, which, in turn, significantly reduced the thoroughness of criticism of the "non-Western path" of development. The author's perspective on the problem is focused on the identification of traditional institutions, their actualization in the modern political process and variants of their socio-political evolution. The authors offer an expanded understanding of the essence of a clan organization that distributes consolidating loyalty directions both horizontally within blood-related communities and vertically, reproducing the hierarchy of connections from the elite top to the rank-and-file members of associations. The authors consider the growth of social movement, self-awareness and public disillusionment with the attempt to reproduce the Western model of social development to be the main factors that actualize the clan organization in the socio-political process of post-Soviet Asian countries. The dynamically developing socio-political reality of the Asian newly independent States actualizes multidirectional vectors of social integration.

Keywords: Post-Soviet space; Central Asia; clans; patron-client relations; clan vertical; socio-political process; regionalization; elite competition; fragmentation

INFORMATION ABOUT THE AUTHORS

\author{
\begin{tabular}{l|l} 
Rekk Dmitry A. & $\begin{array}{l}\text { E-mail: } 100100200 @ b k . r u \\
\text { Postgraduate student }\end{array}$
\end{tabular} \\ Egorov Vladimir G. $\quad$ E-mail: korrka@mail.ru \\ Doc. Sc. (History), Doc. Sc. (Economics), Professor
}

For citation: Rekk D. A., Egorov V. G. Socio-political evolution of Central Asian clans // Social'nye i gumanitarnye znanija. 2020. Vol. 6, No 3. P. 250-259. (in Russ.)

(C) Rekk D. A., Egorov V. G., 2020

This is an open access article under the CC BY-NC-ND license (http://creativecommons.org/licenses/by-nc-nd/4.0/) 


\title{
Социально-политическая эволюция кланов Центральной Азии
}

\author{
Д. А. Рекк ${ }^{1}$, В. Г. Егоров ${ }^{1}$
}

${ }^{1}$ Московский областной государственный университет, ул. Б. Полянка, д. 7/10, стр. 3, Москва, 119180, Российская Федерация

DOI: $10.18255 / 2412-6519-2020-3-250-259$

УДК 321.01/02

Научная статья

Полный текст на русском языке

Статья посвящена клановой организации постсоветских стран Центральной Азии. В последнее время научный интерес к заявленной теме несколько уменьшился, что связано с не реализацией традиционных институтов восточных социумов и снижением влияния либерального мейнстрима на социально-политический процесс в постсоветской Азии. Это, в свою очередь, значительно уменьшило основательность критики «не западного пути» развития. Авторский ракурс исследования проблемы сосредоточен вокруг идентификации традиционных институтов, их актуализации в современном политическом процессе и вариантах их социально-политической эволюции. Авторы предлагают расширенное понимание сущности клановой организации, распространяющей консолидирующие направления лояльности как по горизонтали в пределах кровнородственных сообществ, так и по вертикали, воспроизводящей иерархию связей от элитных верхов до рядовых участников объединений. Основными факторами, актуализирующими клановую организацию в социально-политическом процессе постсоветских стран Азии, авторы считают рост общественного движения, самосознания и общественное разочарование в попытке воспроизводства западной модели общественного развития. Динамично развивающаяся социально-политическая реальность азиатских новых независимых государств актуализирует разнонаправленные векторы социальной трансформации кланов, определяемые либерально-демократической и традиционно ориентированной стратегиями общественного развития. Противоречия с элитной верхушкой, порождаемые традиционным вектором эволюции кланов, неизбежно инициируют «регионализацию» кланов, их консолидацию вокруг повестки, замыкающейся на местные проблемы. Такой «разворот» клановых сообществ может иметь деструктивные последствия, в том числе потенциально ведущие к сецессии.

Ключевые слова: постсоветское пространство; Центральная Азия; кланы; патрон-клиентские отношения; клановая вертикаль; социально-политический процесс; регионализация; конкуренция элит; фрагментация

ИНФОРМАЦИЯ ОБ АВТОРАХ

Рекк Дмитрий Александрович

E-mail: 100100200@bk.ru

Аспирант кафедры политологии и права

Егоров Владимир Георгиевич $\mid$ E-mail: korrka@mail.ru

Доктор исторических наук, доктор экономических наук, профессор, заведующий кафедрой политологии и права

Для цитирования: Рекк Д.А., Егоров В.Г. Социально-политическая эволюция кланов Центральной Азии // Социальные и гуманитарные знания. 2020. Том 6, № 3. С. 250-259.

(C) Рекк Д. А., Егоров В. Г., 2020

Статья открытого доступа под лицензией СC BY-NC-ND (http://creativecommons.org/licenses/by-nc-nd/4.0/) 


\section{Актуальность и постановка проблемы}

Политический процесс и клановая организация постсоветской Центральной Азии, являвшиеся объектом пристального внимания политологов в 1990-е и начале 2000-х гг., постепенно уходят из круга наиболее востребованной исследовательской проблематики. Такая метаморфоза связана с несколькими обстоятельствами. Во-первых, после революционных коллизий начала 90-х гг. прошлого века политический процесс новых независимых государств приобрел относительную стабильность и больше не привлекает исследователей, предпочитающих в качестве предмета своего анализа «острые» сюжеты.

Во-вторых, публичное политическое пространство постсоветской Азии, как и глобальный политический ландшафт, превратилось в элитную «территорию», не доступную описанию ученых.

В-третьих, политологи, тратившие массу интеллектуальных усилий на аргументацию либерально-демократической перспективы общественного развития новых независимых государств, вынуждены признать ее неадекватность постсоветской политической реальности. Описываемая политологами, принадлежащими к этой плеяде, клановая организация представлялась исключительно со знаком «минус» как рудимент, переживший советский период и доставшийся социально-политическому процессу бывших союзных республик в качестве контр-продуктивного наследства, подлежащего искоренению. Однако общественная практика дала основание по-новому оценить место и роль традиционных институтов в современном политическом процессе постсоветских стран Центральной Азии. Очевидно, что, обретая новые сущностные качества, азиатские кланы становятся актуальным социально-политическим феноменом.

О роли неформальных институтов, в том числе кланов в Центральной Азии, казахстанский политолог Данияр Ашимбаев пишет таким образом: «Для всех среднеазиатских республик характерен симбиоз новых практик управления с традиционными системами рекрутирования элит - землячество, кумовство, родство, связи по школьной парте, контакты в рамках делового партнерства. Такова характерная особенность азиатских стран постсоветского пространства: какая бы политическая модель ни была зафиксирована в правовых актах, существует крайне устойчивая традиционная, неформальная система взаимоотношений между элитами. При этом президент в республике должен не только заботиться о своей семейно-родственной группе, но и выступать в качестве верховного арбитра для всех остальных кланов, позиционируя себя «отцом нации»[1, с. 59].

Клановая организация, инкорпорированная в политический процесс, способна активно влиять на выбор социальной перспективы развития новых независимых государств. В этой связи одной из проблем, заслуживающих детального научного анализа, становится проблема определения факторов, обусловливающих устойчивость и жизнеспособность кланов.

\section{Сущностные качества центральноазиатских кланов}

Современная клановая организация Центральной Азии значительно отличается от традиционной, уходящей корнями в глубокое прошлое. 
Модернизация кланов в значительной мере изменила их облик и целеполагание. Структура современных неформальных сообществ вертикально иерархизирована. В основании клановой «пирамиды» располагаются «большие семьи», объединенные по горизонтали кровнородственными, племенными и земляческими отношениями. Обязательным атрибутом «первой ступени» иерархии, интегрирующей простых «общинников», членов патриархальных коллективов, являются местные лидеры из числа наиболее уважаемых знатных сородичей, напоминающих «патеров» прежних традиционных кровнородственных объединений. Нередко таковыми в наше время становятся религиозные авторитеты, объединяющие умму.

Первая, или нижняя, ступень клановой иерархии в наибольшей степени ангажирована традиционными ценностями: справедливости, почитания старших, нормами ислама и т. д.

Верхний уровень иерархии клановой вертикали занимают выходцы из родовых коллективов, продвинувшиеся благодаря поддержке знатных родственников в государственной службе и занимающие место связующего звена между рядовыми родственниками и клановой верхушкой.

Как правило, верх клановой пирамиды занимает малопроницаемый слой, или элитная группа, консолидированная вокруг одной сильной личности, обладающей достаточным административным (властным) ресурсом, чтобы обеспечить доступ к определенному сегменту ренты и финансовых потоков.

Стержневой структурой клановой организации является центральная власть, вынужденная, особенно на первом этапе суверенизации бывших союзных республик, стремиться к достижению баланса клановых интересов.

Таким образом, современная клановая организация стран Центральной Азии представляет собой сложно-структурированную систему, интеграция которой по вертикали и горизонтали обусловлена разными мотивами и приоритетами. Именно в силу сложности и гетерогенности клановые сообщества находятся в динамичном состоянии, определяемом изменениями в расстановке политических сил в высшем эшелоне власти, конкуренцией элитных групп с лидерами местных сообществ за влияние на «общинную массу», степенью социализации кланов.

В научной литературе встречаются попытки редуцировать клановую организацию постсоветской Азии до патрон-клиентских отношений или исключительно патриархальных сообществ, «ориентированных на родство образований» [2, с. 19]. Кланы как «региональную сеть» характеризует исследователь казахстанских неформальных сообществ С. Ф. Старр, эксперт католического университета Левенса Жанна Хегай, понимая под азиатскими кланами союз «нескольких семей, связанных друг с другом на основе родства», тем не менее говорит о том, что таковые «даже если превращаются в регионально объединенные альянсы, могут существенно влиять на политические, социальные, экономические процессы в пяти странах» Центральной Азии [3, с. 94].

Наиболее продуктивной представляется точка зрения Кэтлин Коллинз, по мнению которой клановая лояльность распространяется как по горизонтали (как правило, между членами, связанными кровным родством), так и по вертикали, связывая элитные и неэлитные уровни иерархии. «Элитные члены кланов, предоставляя возможности или помощь участникам соответствующих сетей, взамен рассчитывают на их личную лояльность и уважение для того, чтобы поддержать свой статус» [4, p. 142]. 


\section{Кланы и актуальный центральноазиатский политический процесс}

Современный политический процесс постсоветских азиатских республик, интегрирующий клановые сообщества, характеризуется двумя основными обстоятельствами. Во-первых, очевидностью нерелевантности либерально-демократической перспективы, продиктованной желанием политической элиты этих стран воспроизвести западный опыт общественного развития. Весной 2018 года «елбасы» Н. Назарбаев при обсуждении учебников, создаваемых в соответствии с проектом «Новое гуманитарное знание. 100 новых учебников на казахском языке», заявил: «Казахстан идет к демократии по особенному пути развития». «Я с самых первых дней независимости возглавляю эту страну, оправдываю доверие народа». Сколько раз с Запада говорили: «Внедрите демократию как у нас, как в Америке, как на Западе». Мы казахи, мы не американцы, не немцы, не англичане» [5].

В связи с осознанием иллюзорности «третьей волны демократии» (по С. Хантингтону), которая должна была универсализировать политическое пространство азиатских постсоветских государств, актуализировались традиционные ценности, фундирующие кровнородственные сообщества и создающие возможность использования в политической модернизации конструктивного потенциала кланов. На такую возможность, ссылаясь на движение кенийских кланов «Харамби», указывает ведущий научный сотрудник Института истории и этнологии им. У. Валиханова (Казахстан) Б. М. Сужиков. По этому поводу он пишет: «Гуманитарии наших дней, включая зарубежных историков, пытаются каким-то образом реставрировать феномен групп, основанных на родственных связях, сделав формой социальной организации и политической жизни современности. Их схемы выстраиваются по лекалам, например, движения «Харамби» в Кении, когда кланы мобилизуют свои ресурсы для достижения определенных целей, или методом адаптации родоплеменной идентичности к современным условиям на основе «корпоративности» [6]. В политической истории Степи действительно наличествует достаточно иллюстраций стройной правовой организации консорции и взаимовыручки в казахском обществе. Как отмечала американский исследователь казахского права XIX века Виржиния Мартин, «это был «живой» организм, состоявший из норм и процедур, формировавших понятия справедливости, ответственности, морали...» [7].

В 2012 году первый президент Казахстана Н. Назарбаев заявил о необходимости построения в Казахстане общества Всеобщего труда как альтернативы западному обществу потребления [8].

Невозможность укоренения либерально-демократического порядка западного образца и необходимость консервативной модернизации центральноазиатских политических режимов обусловливались отсутствием в постсоветской реальности его основного элемента, а именно правового пространства. Уважение к закону формировалось на Западе вместе с институтом частной собственности, без которого последний функционировать не может. На эту особенность формирования западной цивилизации обращали внимание еще представители австрийской школы политэкономии [9, с. 33-34].В отсутствии правового порядка в республиках Центральной Азии гарантом прав и свобод граждан становилась авторитарная персонифицированная власть (не противоречащая обычаям и традициям азиатских народов) и традиционные институты, в том числе и кланы, которые, особенно на начальных этапах становления независимости, в значительной мере восполняли недостаток управляемости социумов. 
Казахстанский правозащитник Е. Жовтис, выступая на ежегодной конференции обществ изучения центральной Евразии (Central Eurasian Studies Society), организованной в октябре 2014 г. в Колумбийском университете в Нью-Йорке, сказал: «В современных обществах эволюция экономических и юридических основ частной собственности способствовала выработке представлений о личных правах и свободах. В постсоветских странах данный процесс не прижился» [10]. А другой западный эксперт М. Ларуэль заметил, что правовые институты Центральной Азии являются несамостоятельными и только «имитируют необходимый антураж легитимации квазисистемы» $[11$, с. 87].

В свою очередь, К. Коллинз иллюстрирует важность кланового механизма управления социумами данными оригинального социологического исследования. Гражданам сельской местности Киргизии и Узбекистана было предложено ответить на вопрос: «Если Вам нужна финансовая помощь, куда Вы обратитесь». Ответы на вопрос представлены в таблице 1.

Если Вам нужна финансовая помощь, куда Вы обратитесь?

Таблица 1

(в процентах от общего числа респондентов) [12, с. 178]

\begin{tabular}{|c|r|r|r|r|r|}
\hline Страны & Банки & \multicolumn{1}{|c|}{$\begin{array}{c}\text { Государственные } \\
\text { агентства }\end{array}$} & Мечеть & $\begin{array}{c}\text { Сельская } \\
\text { община } \\
\text { (колхоз }\end{array}$ & $\begin{array}{c}\text { Родственные, } \\
\text { клановые } \\
\text { сообщества }\end{array}$ \\
\hline Киргизия & $1 \%$ & $2 \%$ & 0 & $4 \%$ & $93 \%$ \\
\hline Узбекистан & $2 \%$ & $3 \%$ & 0 & $3 \%$ & $92 \%$ \\
\hline
\end{tabular}

Приведенные в таблице данные говорят о том, что кланы в Центральной Азии остаются действенным механизмом социальной организации. Кроме того, согласно исследованиям К. Коллинз, в разрешении конфликтов 97 \% сельских жителей в Киргизии и 96 \% в Узбекистане предпочитают в качестве единственного источника правового порядка поддержку со стороны собственного клана (Таблица 2).

Таблица 2

Когда вам нужно разрешить конфликт, куда Вы обратитесь за помощью?

\begin{tabular}{|c|r|r|r|r|r|}
\hline Страны & Суды & $\begin{array}{c}\text { Государственные } \\
\text { агентства }\end{array}$ & Мечеть & $\begin{array}{c}\text { Сельская } \\
\text { община } \\
\text { (колхоз) }\end{array}$ & $\begin{array}{c}\text { Родственные, } \\
\text { клановые } \\
\text { сообщества }\end{array}$ \\
\hline Киргизия & 0 & 0 & 0 & $3 \%$ & $97 \%$ \\
\hline Узбекистан & 0 & 0 & $2 \%$ & $2 \%$ & $96 \%$ \\
\hline
\end{tabular}

В связи с необходимостью смены политической повестки клановой организации Центральной Азии очевидно наметился разлом между интересами в большей степени вестернизированной элитной верхушки и рядовыми членами традиционных сообществ.

В этой связи многие исследователи отмечают реинтеграцию клановых сообществ вокруг региональных лидеров, способных предложить консолидирующие идеи, лежащие даже вне легального пространства. 
Во-вторых, политический процесс новых независимых государств Центральной Азии характеризуется новой динамикой и качественными трансформациями, связанными с ростом общественного самосознания и нарастанием политической активности граждан этих стран. Волна протестного движения буквально захлестнула Центральную Азию.

Общественные акции, инициируемые тяжелым материальным положением населения, происходят с завидной периодичностью и по любому поводу. Достаточно указать на всплеск общественных выступлений, связанных с переименованием столицы Казахстана, волнения 2019 г. в узбекском Ургенче. В Киргизии и Таджикистане народное возмущение выливается в массовые акции, спонтанно и каждый раз грозит перерасти в вооруженные конфликты [13; 14; 15].

Кланы, составляющие органическую часть политической надстройки, испытывают, как и центральная власть, необходимость в социализации.

Как показывает общественная практика, существует возможность социальной мобильности клановой организации как в направлении, определяемом форматом партикулярных интересов вестернизированных элитных групп, так и в потенциальной консолидации клановых сообществ вокруг общенациональной повестки. В актуализации второго варианта социальной перспективы критически важная роль принадлежит центральной власти, которая с целью самовоспроизводства вынуждена адаптироваться к условиям возросшей общественной активности и направить усилия на презентацию повестки, способной преодолеть клановую разобщенность социумов.

Имея в виду наличие самых различных групп влияния, стремящихся обрести социально-политический статус за счет «укоренения» в клановой организации: олигархического, экстремистского, религиозного, прозападного и т. д., перспектива кланов Центральной Азии выглядит неоднозначно.

Согласно данным проведенного казахстанским агентством «365info» опроса (август 2019 г.), почти половина респондентов (45 \%) считает, что нарастание дестабилизационных процессов в стране будет продолжаться, чему способствует «высокий уровень неформальных патрон-клиентских отношений» [16].

\section{Направления социально-политической мобильности центральноазиатских кланов}

Таким образом, динамика социально-политического процесса в постсоветских азиатских республиках неизбежно порождает их подвижность, не имеющую однозначного варианта развития.

Нарастание общественного скепсиса по поводу «проекта» вестернизации новых независимых государств актуализируется разломом клановой иерархии по линии, отделяющей элитный и «общинный» уровни. Элитные группы, находящиеся на «вершине» клановой пирамиды и использующие влияние на традиционные сообщества с целью укрепления собственного статуса, гарантирующего доступ к административному и материальному ресурсу, в большей степени чем другие граждане, испытавшие влияние модернизационных процессов, пытаются «развернуть» вектор общественной мобильности кланов в теряющее популярность направление либерально-демократических трансформаций, а точнее сказать, его имитацию. 
В свою очередь, неизбежная социализация традиционных институтов актуализирует их конструктивный потенциал, а именно консолидации вокруг общенациональных ценностей справедливости, сохранения культурной самобытности, традиций и обычаев.

Наличие указанного «разлома» проецируется в разновекторности политического процесса стран Центральной Азии. Например, весной 2019 г. в столице Казахстана прошли две протестные акции с совершенно отличающимися социально-политическими ориентирами: выступление женщин под лозунгом «Жилье нашим детям!», призванное обратить внимание властей на жилищную проблему, усугубляющуюся по мере роста неравенства в стране, и молодежные акции А. Тулесовой и Б. Толыжбековой «От правды не убежишь», направленные на срыв избирательной компании президента страны. По оценкам экспертов, имеется достаточно оснований полагать, что молодежные протесты инициированы элитными группами, стремящимися реализовать собственные амбиции [17].

Безусловно, молодежная среда в большей степени, чем остальное гражданское сообщество, подвержена влиянию разнонаправленных политических сил, в том числе определяющих инициацию социальной мобильности кланов. 0 наличии разнонаправленных предпочтений молодежи стран постсоветской Центральной Азии говорят результаты проведенного контент-анализа содержания популярных блогов (Таблица 3) [18; 19; 20; 21; 22].

Таблица 3

Контент-анализ содержания популярных блогов

\begin{tabular}{|l|r|r|r|r|}
\hline \multicolumn{1}{|c|}{ Вопросы } & Казахстан & Кыргызстан & Узбекистан & Таджикистан \\
\hline $\begin{array}{l}\text { Либерально- } \\
\text { демократический } \\
\text { порядок (как на Западе) }\end{array}$ & $64 \%$ & $34 \%$ & $31 \%$ & $18 \%$ \\
\hline $\begin{array}{l}\text { Хочу, чтобы в стране } \\
\text { реально правил народ }\end{array}$ & $30 \%$ & $46 \%$ & $37 \%$ & $34 \%$ \\
\hline Поддерживаю власть & $6 \%$ & $10 \%$ & $32 \%$ & $48 \%$ \\
\hline
\end{tabular}

Разнонаправленные социальные ориентиры, демонстрируемые результатами контент-анализа, в полной мере отражают возможные векторы канализации клановой эволюции. Подтверждением вариативности такой эволюции может служить опыт общественного развития, например, Турции, в полной мере реализовавшей путь вестернизации, и, например, Ирана, двигающегося в направлении имплементации традиционных ценностей.

Вместе с тем отрыв кланов постсоветской Центральной Азии от «руководящего и направляющего» влияния элитных групп несет в себе не только конструктивный потенциал. Разворот в сторону традиционного этноса неизбежно сопровождается ростом влияния местных религиозных родоплеменных лидеров, целеполагание политической деятельности которых далеко не всегда совпадает с общенациональными интересами. Мало того, существует опасность использования кланов местными авторитетами в нелегальных целях или сепаратистских устремления, ведущих к фрагментации стран. 
Подтверждением сказанного может служить, например, недавняя история с выборами акима (главы района) Аксыйского района Джалл-Абадской области Киргизии, которым препятствовали представители местных «уважаемых аксакалов». Об этой ситуации 6 марта 2019 г. заявил первый вице-премьер страны Кубайтбек Боронов: «По акиму Аксыйского района очень много предложений и споров. Скажем откровенно: в том числе споры из-за племенного деления. Почему бы не говорить об этом открыто? Будем и дальше молчать? Мы должны открыто говорить о наших болячках» [23].

\section{Заключение}

Таким образом, феномен кланов сохраняет актуальность и жизнеспособность в социально-политическом процессе республик постсоветской Центральной Азии. Актуальности клановых сообществ, в том числе, способствует динамика происходящих в этих странах трансформаций, прежде всего связанных с ростом общественной активности и самосознания и проявлением нерелевантности «проектов» вестернизации новых независимых государств.

В условиях динамичных изменений социально-политической реальности постсоветских стран Азии клановая организация испытывает влияние разнонаправленных векторов эволюции, определяемых либерально-демократической и традиционно ориентированной стратегиями общественного развития.

Важнейшая роль в окончательном укоренении кланов в одном из направлений социальной динамики зависит прежде всего от способности центральной власти государств постсоветской Азии генерировать повестку национальной консолидации.

\section{Ссылки / References}

1. Сысоев Т. Матрица постсоветской элиты // Эксперт. 2019. № 45-46. С. 54-59.

2. Рогожина Г. А. Клиентализм в рекрутировании политических элит в Российской Федерации и постсоветских государствах Центральной Азии: дис. ... канд. полит. наук. М., 2010. 241 c.

3. Starr F. Clans, Authoritarian Rulers and Parliaments in Central Asia. Washington, 2006. P. 6-25.

4. Collins K. Clans, Pacts, and Politics in Central Asia // Journal of Democracy. 2002. Vol. 13. P. 137-152.

5. Назарбаев вспомнил о недемократичных страницах истории США // Журнал «Орбита Спутник»: сайт. [2019]. URL: https://www.ru.sputnoknews.ratiya.html (дата обращения: 16.12.2019).

6. Schatz E. Modern Clan Politics: The power of Blood in Kazakhstan and Beyond. L., 2004. 280 p.

7. Сужиков Б. М. Не надо думать, что человеческая натура кардинально изменилась, просто лекала западной демократии стали диктовать иные формы поведенческих практик // «История Казахстана»: сайт. [2020]. URL: https//e-history.kz/ru/expert/view/10 (дата обращения: 20.05.2020).

8. Назарбаев Н. Социальная модернизация Казахстана. Двадцать шагов к обществу Всеобщего труда // Департамент юстиции Костанайской области: сайт. [2020]. URL: kstadilet.gov.kz/ru/articles-innertobshchestvo-vseobshego-truda-22 (дата обращения: 17.05.2020). 
9. Мизес Л. фон. Социализм. Экономический и социальный анализ. М.: Cattallaxy, 1994. $416 \mathrm{c.}$

10. Жовтис Е. Кто попирает право частной собственности в центральной Азии? // Портал «За рубежом»: сайт. [2019]. URL: https://www.zarubejom.ru/news/show/14357.html (дата обращения: 01.01.2020).

11. Laruelle M. Kazakhstan: Nation-branding, Economic Trials, and Cultural Changes .Washington: The George Washington University, 2017. 217 p.

12. Collins K. The Political Role of Clans in Central Asia // Comparative Politics. 2003. January. P. 171-190.

13. Люди устали. Протесты в 2019 году: причины и последствия // Портал «Аззатык»: сайт. [2019]. URL: //https://www.rus.azattyg.org/akazakhstan-2019-year-protest-sausesand-conseguence/3031048.html (дата обращения: 17.01.2020).

14. Волнения в Ургенче. Что произошло? // Портал «Anhor»: сайт [2020]. URL: https://www.anhor.uz/society/volneniya-v-urgenche-chto-proizoshlo (дата обращения: 25.01.2020).

15. По данным генерального прокурора в Таджикистане в 2019 г. было совершено 1060 преступлений экстремистской направленности, что на 306 случаев больше, чем в 2018 г. // Портал «Авеста»: сайт. [2020]. URL: https://www/avesta.tj/2020/01/27/vtajzhikistane-za-popytky-organizatsii-buntov-k-novym-srokam-prigovoreny-70-zaklychennyh (дата обращения: 16.01.2020).

16. Что ждет Казахстан в ближайшие 5 лет? // Портал «365 инфо»: сайт. [2019]. URL: 365info.kz/2019/09/chto-zhdet-kazahstan-v-blizhajshie-10-let-eksperty (дата обращения: 11.12.2019).

17. Примаков Е. Нынешние протесты, интеллигенция, элиты и революция // Портал «Вести.ру»: сайт. [2020]. URL: vesti.ru/doc.html.?id=3179585 (дата обращения: 17.03.2020).

18. Что могут блогеры в современном Узбекистане // Новости «Stanradar»: сайт. [2019]. URL: stanradar.com/news/full/38713-chto-mogut-blogery-v-sovremennom-uzbekistane.html (дата обращения: 11.12.2019).

19. тоП-30 самых популярных казахстанских знаменитостей в Instagram // Pandaland.kz: сайт. [2020]. URL: pandaland.kz/articles/semya/raznoe-i-poleznoe-270/top-30-samyhpopulyarnyh-kazahstanskih-znamenitostej-v-instagram (дата обращения: 15.07.2020).

20. Топ-10 популярных кыргызстанских пользователей Instagram. Кто они // «Спутник»: сайт. [2020]. URL: https://ru.sputnik.kg/society/20181103/1041846416/kyrgyzstaninstagram-akkaunty-populyarnost.html (дата обращения: 17.07.2020).

21. Юксалиш назвал топ-30 общественных активистов // Газета.ру: сайт. [2019]. URL: www.gazeta.uz/ru/2019/10/23/community-activists/ (дата обращения: 10.07.2020).

22. Шесть перспективных таджикских блогеров, которых интересно смотреть // Портал «Limu.tj»: сайт. [2020]. URL:

https://limu.tj/main/vseti/6_perspektivnykh_tadzhikskikh_blogerov_kotorykh_interesno_smo tret/ (дата обращения: 03.04.2020).

23. Кунешова Р. Выборы акима Аксы. Правительство заявило о родоплеменном делении // Радио «Азаттык»: сайт. [2019]. URL: https://rus.azattyk.org/a/kyrgyzstan-aksy-akimelection/29808151.html (дата обращения: 25.06.2020). 